\title{
AS EMPRESAS BINACIONAIS E SUA \\ EFETIVIDADE NA LIBERDADE DE \\ ESTABELECIMENTO NO MERCOSUL.
}

Heloisa Helena de Almeida Portugal *

SUMARIO: I. Introduca, 2. Instrumentos e principios para o alcance do equilbrio economico no MERCOSUL 3.As Associaçoes Empresariais: as Jom Ventures 3. 1. As Empresas Binacionais Argentino-Brasileirts. 3.2. As Binacionais ArgentinoBrasileras como instrumentos vidbilizadores da Liberdade de Estabelecimento no Mercosul. 4.Conclusão. 5.Bbliografia.

SUMMARY: I. Introdution. 2. Instrumentos and principles for the reath of the economical balaner in MERCOSUL. 3. The Enterprises Associations Yont Ventures. 3.1.The Empresas Binationals Argenines-Brazilians. 3.2. Bnationals ArgentinesBrazilians as viability instruments of the Fredom of Establishment in Mercosul. 4. Conctusion. 5.Biblography.

UBERSICHT: 1.Einfühung. 2. Instrumente und Gundsatze zur Erreichung des wirtschaftlichen Gleichgewichts im Mercosul. 3. Untementensverbindungen die Jont Ventures. 3.1. Die binationalen argentinisch - brasilianischen Untemehmen. 3.2. Diese Untemehmen als Instrumente zur Erreichung der Niederiassmgs friheit im Merosul. 4.Schlussfolgerung, 5.Biblographie.

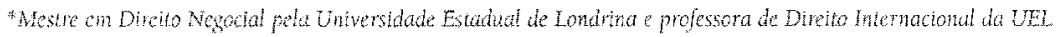
GACCAR
} 
RESUMO: O processo de integraça, encetado no contexto do Mercosul mostra-se também atraves do dinamismo do setor privado $e$ da imperatividade dos fuxos comerciais. Como fundamentos da integracao encontram-se as liberdades de circulaçäo de bens, serviços, pessoas capitais, $e$, no caso especifico, a liberdade de estabelecimento. Tais hberdades são alcançadas através da coordenaçăo de politicas macroeconomicas e setoriats, como preceitua o Tratado de Assunçăo, não sendo esta uma tarefa fácil. Neste veio, já em seara de aproxinaçăo politico-economica entre Brasil e Argentina, em 1990, firmoli-se o Estatuto das Empresas Binacionais, que se apresenta como foma associativa setonal e bilateral facilitadora do estabelecinento empresarial e viabilizadora do crescimento do fluxo comercial. A estrutura juridica criada pelo Fstatuto revela caminhos eficazes e suavizadores do impacto da integraçäo reduzindo as antinomias legislativas que necessitam de hamonizaça. As empresas binacionais podem ser utilizadas como instrumentos da aplicabilidade e efetividade da liberdade de estabelecimento no Mercosul.

ABSTRACT: The integration process, begun in the context of Mercosul it is also shown through the dynamism of the private section and of the imperatividade of the commercial flows. As foundations of the integration are the freedoms of circulation of goods, services, people and capitals, and, in the specific case, the establishment freedom. Such freedoms are reached through the coordination of politics macrocconomicals and sectorial, as it sets down the Agreement of Assumption, not being this an easy task. In this vein, already in seara of political-economical approach between Brazil and Argentina, in 1990, Binational Enterprises's Staute was fim, that come as sectorial and bilateral associative form faclitative of the managerial establishment and viabilizadora of the growth of the commercial flow. The juridical structure created by the Statute he/she reveals effective and smoothing roads of the impact of the integration reducing the legislative antinomias that need hamonization. The compantes binacionais can be used as instruments of the aplicability and effectiveness of the establishment freedom in Mercosul. 
7USAMMENFASSUNG: Das Integrationsverfahren, daß im Kontext des Mercosul engefuhrt wird, zeigt sich auch durch der Treibkraft der privaten Sektoren und durch die Kraft der Handelsrichtung. Als Fundamenten der Integration dienen die Verkehrsfreiheiten von Gutem, Dienst, Personen und Kapital und in der spezifischen Fall dient der Niederlassungsfreheit. Die eben genannten Freiheiten werden durch der Koordinierung von sektorielle und makroökonomischen Politke erreicht, gemaj des Assumptionstraktat und stellt keinen leicht Aufgabe dar. In diese Richtung wurde de Statuten des binationalen Unternehmen unterschrieben, daß sich als bilateral und sektorielle assoziative Form für die Erleichterung von Unternehmensniederlassung und für die Forderung def hommerzicle Fluorswachstum darstellt. Die juristische Strukdu, die vom Statut konzipiert ist, eroffnet leichte und wirkungsvolle Wege un die megrationsimpakt zu vermeiden und minderte daduth auch die legislative Widersprühen, die ein Hamonisierung verlangen. Die binationale Untemehmen könen als Werkeuge für die Durchsetzbarkeit und Wirksamkeit der Niederlassungsfreiheit in der Mercosul dienen.

PALAVRAS-CHAVE: Mercosul. Liberdade de estabelecimento. Emplesas binacionais. Acordos setoriais. Joint ventures. Harmonizaça legislativa.

KEY-WORDS: Mercosul. Establishment Freedom. Binational Enterprises. Sectorial Agrements. Joint Ventures. Legislative Harmonization.

SCHLUSSELWÖRTER: Mercosul, Unternehmungsfreiheit. Binationalen Unternehmen. Sektorielle ubereinkommen. Joint ventures. Legislative Hamonisierung.

\section{Introdução}

Podem as empresas binacionais ser instrumentos viabilizadores da liberdade de estabelecimento no Mercosul? A busca por esta resposta 
consiste no estudo do Estatuto das Empresas Binacionais Argentina - Brasil como instrumento da liberdade de estabelecimento, preconizada pelos sócios do Mercosul como requisito do processo integracionista proposto.

Em processos de integração de forma geral coloca-se a necessidade de coordenar as politicas economicas e harmonizar as legislaçoes respectivas, que devem ser concebidas não como um fim em si mesmas, mas como instrumentos funcionais desse objetivo maior que é a integração, O conceito de harmonização implica, justamente, efetuar certas mudanças nos ordenamentos nacionais para criar uma similitude entre eles e facilitar com isso o atingimento do objetivo principai.

O espaço juridico transnacional criado pela aldeia global comporta a adoção de modelos ou formas de intercambios novos e diversos, onde as empresas, como principal vetor deste processo, associam-se criando uma forma altemativa aos conglomerados e multinacionais: o ponto nodal do presente artigo.

As empresas binacionais apresentam-se como tal forma de colaboração. Instrumentos oriundos não propriamente do Mercosul, mas de um processo de colaboração entre países que vislumbram a integraça e expansão. Institutos pouco conhecidos pelos aplicadores do direito, sua importância dá-se pela possibilidade da empresa ser constituida nacional em ambos os países: Argentina e Brasil.

Sem embargo, o Estatuto não toca no direito societário do Brasil ou da Argentina, uma vez que o processo de integração está concebido não como resultante de um regime comum estabelecido por um direito comunitário, mas como a conjunça de um projeto intergovernamental no qual cada pás preserva inteiramente sua soberania.

Afirmar que uma empresa é nacional significa ter acesso à linha de créditos especiais, tratamento tributário equiparado à empresa de direito interno e, a participaçäo em concorrencias públicas. Superam-se as barreiras tatifárias e nào-tarifarias impostas à empresa estrangeira.

Os principios da liberdade de estabelecimento preconizados pelo Tratado de Assunção e base para a integração regional poderiam estar 
satisfeitos com os instrumentos juridicos do Estatuto das Empresas Binacionais. Haveria grande ganho ao expandir seus preceitos para os sócios do Mercosul, pois o trabalho de harmonização legislativa seria simplificado. As estruturas empresariais utilizadas seriam as já existentes no ordenamento juridico de cada país, ou seja, o impacto da integração estaria suavizado.

Vislumbra-se, no decorrer deste estudo, que o Estatuto das empresas binacionais brasileiro-argentinas originou-se da concordância de vontades entre os governos do Brasil e da Argentina, e como necessidade de uma maior integraçäo econômica entre os dois países vizinhos.

O Tratado em si buscou conjugar dois interesses comuns, quais sejam, a constituição, ou melhor, a união entre duas nacionalidades diversas no sentido de tentar harmonizar as legislaçóes, criando-se uma lei única para que as empresas dos dois Estados interajam entre si ampliando portanto os seus mercados. Com o escopo de se tornarem mais estreitas as relaçoes cometciais, rumo à consolidação do Mercado Comum do Cone Sul, cujo principal sustentáculo funda-se no bom relacionamento entre os dois paises em tela.

\section{Instrumentos e principios para o alcance do equilibrio econômico no MERCOSUL}

O Tratado de Assunção tem por objetivo a integração econ6omica entre os paises signatários, e, desta forma, pertence à categoria dos tratados de integração. Isto porque, a integração caracteriza-se por ser um fenômeno específico e delimitado pela prática internacional, e, não apenas cria, mas exige um regramento peculiar. De maneira que consta do preâmbulo do Tratado de Assunção o equilibrio económico, como um dos princípios para atingir o desenvolvimento econömico.

Este principio não quer dizer que os Estados-partes necessitem estar em igualdade de condiçóes, até porque, isso seria inviável à medida que cada Estado possui suas particularidades. Mas, independente disto, deve existir o mínimo de desenvolvimento dos Estados-partes para que seja criado um 
mercado com igualdade de direitos e obrigaçoes para os seus integrantes. 0 equilibrio visa determinar que a integração não ocorra com o sacrificio de um Estado, em proveito dos demais, sem um devido programa de compensaçāo para a região.

Tal se dá, em razào de que um processo de integração faz com que deteminadas regióes se especializem em determinados produtos, diminuindo a possibilidade de outras regioes concorrerem no mercado comum, com aqueles mesmos produtos. O princípio do equilibrio deve predominar nas tomadas de decisóes dos entes da integração, procurando estabelecer mecanismos de compensação para os segmentos atingidos pelo processo da integração.

Na esfera nacional, cumpre velar para que a dimensão MERCOSUL seja incorporada ao processo de formulaça de politicas públicas, em especial em seu vetor economico e, de forma ampla, ao planejamento governamental de médio prazo. No que se refere aos fluxos de comércio entre os países membros, um dos principais desafios é o de evitar que desequilibrios bilaterais conjunturais possam obstaculizar, ou mesmo frear, as correntes de intercâmbio que foram criadas ou intensificadas no periodo recente

No que pertine à liberdade de estabelecimento, faz-se mister mencionar os aspectos econômicos. Em virtude disto, deve-se atentar para o elemento fundamental contido no quarto parágrafo do artigo $1^{\circ}$ do Tratado de Assunção, qual seja a coordenação de políticas macro-econòmicas e setoriais entre os Estados-partes.

No que diz respeito à coordenação de políticas macroeconômicas do MERCOSUL, as atividades nessa área vêm se realizando gradualmente e de forma convergente com os programas de desgravação tarifária e eliminação de restriçōes não tarifárias. Esse esforço busca assegurar condições adequadas de concorrencia entre os Estados Partes e a evitar que eventuais descompassos nas políticas dos paises partes favoreçam ou prejudiquem artificialmente a competitividade de bens e serviços.

Essa politica é essencial na medida em que assegura condiços adequadas de concorréncia e também oferece segurança aos demais Estados- 
partes, eis que oferece garantias compensatórias em caso de desestabilizaçäo econômica de um dos países integrantes do MERCOSUL. Garantindo, assim, a integridade do bloco econômico.

E importante notar que estes acordos setoriais não deverão criar cartéis, trusts $^{2}$ ou outras formas de abuso do poder econômico e práticas desleais de comércio. Com o intuito de evitar este problema, os acordos setoriais devem ser submetidos a uma análise prévia dos subgrupos de trabalho do MERCOSUL.

No âmbito do Tratado de Assunção um dos instrumentos de fundamental importância para a regulamentaçăo e harmonização legislativa no MERCOSUL consiste no disposto do artigo 5", "d" do Tratado de Assunção", onde possibilita a adoção de acordos setoriais, com a finaliaade de otimizar a utilizaçăo e mobilidade dos fatores de produção e de atingir escalas eficientes.

Na análise dos atos normativos do MERCOSUL, uma primeira precaução é evitar-se um comparativismo com a realidade da União Européia, sem a consciência de que se trata de fenômenos substancialmente diferentes. Embora ambos sejam realidades dinàmicas, na União Européia, tanto os ógãos e suas funçöes, como as realizaçoes nomativas se encontram cristalizadas desde o primeiro tratado que as instituiu (o Tratado de Paris que criou a CECA), configurando-se sob a supranacionalidade.

Feita csta ressalva, muito importante para o MERCOSLL, é a decisão n. 3, do Conselho do Mercado Comum, sobre Termos de Relerência para Acordos Setoriais, adotada em dezembro de $1991^{4}$. Esta decisão é um

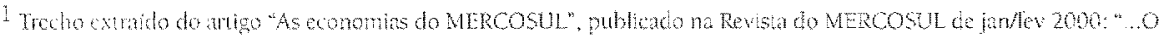

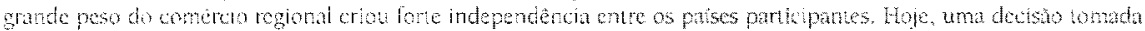

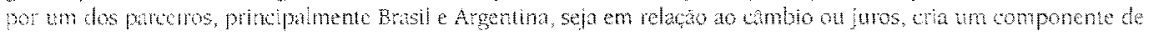

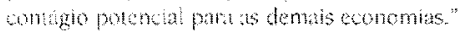

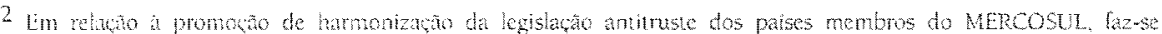

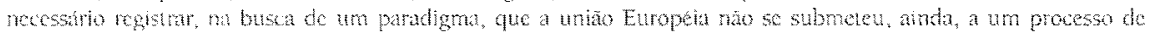

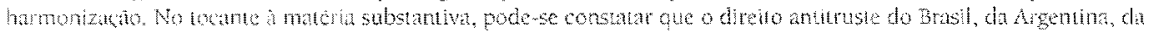

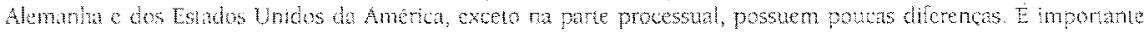

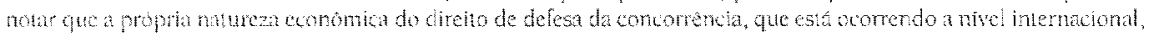

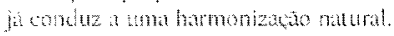

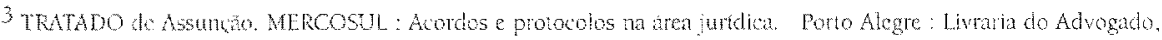
1906, p. 22,

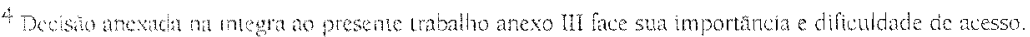


incentivo às empresas interessadas em associar-se com outras e um veículo para a liberdade de estabelecimento, tendo em vista que visa facilitar a instrumentaçäo do Tratado de Assunção, pois os Acordos Setoriais são formas eficazes para a constituição do Mercado Comum ${ }^{5}$.

Estes devem acelerar a integraçăo e favorecer a racionalidade na especializaçăo intra-setorial, baseada nas respectivas vantagens comparativas. Os Acordos Setoriais devem, ainda, considerar e favorecer o intercâmbio de bens e serviços, o fluxo de capitais, o desenvolvimento e a incorporação de tecnologia.

As associaçós empresariais têm difundido-se com bastante velocidade no mundo como forma célere e de custo reduzindo para o favorecimento do fluxo comercial internacional, onde cria-se o sistema de produção em rede. Tais associaçōes são denominadas Joint Ventures.

\section{As Associações Empresariais: as Joint Ventures}

A expressão joint venture, originária do direito norte-americano, significa de maneira geral um uma associação de empresas, onde joint significa um conjunto, uma associação, e venture, uma aventura, um negócio, um projeto, uma empresa. Esta figura juridica emergiu da prática norteamericana, onde empresas se associam somando os esforços e dividindo os riscos e lucros sob um nova pessoa jurídica, sua nomenclatura não tem correspondente na língua portuguesa, mas encontramse fundamentada na lei das sociedades anônimas, sob a êgide dos grupos associativos.

A principal características das joint ventures é a realizaça de um projeto comum, empreendimento de médio ou longo prazo, e em razão de sua natureza, podem ser utilizadas para as mais diversas aplicações, nos setores industriais, comerciais e agropecuários, assim como nos setores imobiliários, extrativistas, hoteleiros, de compra e venda de mercadorias, valores e outros bens móveis, construção de grandes obras, execuçäo de servicos públicos e outros.

5 KIRMSLR, jose Raul Tores Reftexiones ante la Problemática Jundica cel Merostr - El Derecho frente al Desafo de la Integuton Indeoninent Edwom: Assuncion, 1998. p. 52 
A joint venture é a relaçāo contratual de duas ou mais pessoas físicas ou juridicas, nacionais ou estrangeiras, que sem perder sua própria identidade e autonomia, vinculam-se com o objetivo de realizar uma atividade economica determinada, podendo aportar a tais propósitos ativos tangiveis ou intangiveis que deveräo ser explorados unicamente visando o objetivo especifico do contrato e em um lapso de tempo determinado previamente ou vinculado ao cumprimento do objeto'.

Caracteriza-se como uma associação para realizar um negócio jurídico empresarial específico e singular, sendo utilizada tanto para cooperação temporal, com objeto singular e tempo determinado, como, em grande escala nos paises do Mercosul, para a cooperação empresarial duradoura, caracterizando-se como forma alternativa de investimento estrangeiro.

A natureza juridica da joint venture encontra-se ainda controvertida, tendo em vista năo haver correspondentes no ordenamento jurídico nacional, porem sua noção exprime uma base contratual, constituindo-se então como uma modalidade contratual atípica, que consente ampla liberdade as partes para escolher o específico instrumento juridico através do qual se consubstanciará7.

Assim, quando a operação de joint venture encontra-se influenciada pelo meio em que se desenvolve, seja pela atividade ou pelo país, tornando incerta sua delimitação, basta verificar se estāo presentes seus elementos constitutivos. Se a figura jurídica colocada à frente reunir todos os elementos básicos pode-se afirmar ser um contrato de joint venture. Os elementos são: natureza contratual, objeto especifico, prazo, gestão mútua, controle conjunto, distribuição de resultados, intuitu personae, natureza fiduciária e responsabilidade ilimitada".

Quando as partes tèm a mesma nacionalidade, a operação conjunta define-se nacional ou do méstica, enquanto que se a matriz geografica for diferente da nacionalidade de uma delas, fala-se em joint venture internacional.

\footnotetext{
${ }^{6}$ RIOS, Anibal Sierral la. Joint venture intenacional. Buenos Aires: Depalma, 1990.p.69.

7 PEREREA NETO, Mario. Joint ventures com a Uniăo Europẻa, Sâ Paulo: Aduaneiras, 1995 p. 64

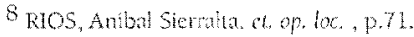


As joint ventures são consideradas grupos associativos por coordenação, este tipo de agrupamento pode ser caracterizado por lormas contratuais, regidas pela teoria geral dos contratos, primando pela autonomia da vontade.

Uma das formas de associação em joint venture é a empresa binacional criada pelo Estatuto das Empresas Binacionais Brasileiro Argentinas, Tais empresas constituem uma formação especial, sendo parte do gênero joint venture por advirem da parceria entre empresas.

De uma maneira geral, empresas binacionais são aquelas que envolvem dois Estados, inseridas na categoria das multinacionais ou transnacionais, e sua criaçäo näo está necessariamente atada à existência de un regulamento especial, sendo flexivel sua formulação.

As binacionais constituem uma forma de parceria entre os Estados sendo um elo entre o público e o privado, na medida em que aquele facilita, através de incentivos, facilitaçōes fiscais e regulamentos próprios, o estabelecimento comercial privado.

Nota-se que a designaçăo binacional reporta-se ao fato das empresas serem formadas por capital de dois Estados e não como indicação da nacionalidade de pessoa jurídica. A empresa terá como sede o país de constituição, estando submetida à legislação interna deste. Estas empresas foram criadas para melhor operacionalizar os investimentos bilaterais, facilitando o intercâmbio comercial entre Brasil e Argentina.

Estatuto das Empresas Binacionais Brasil-Argentina, apesar de não ser um instrumento originado em consequência do Tratado de Assunção, consiste em um importante instrumento no processo de integração regional. Assinado em 06 de julho de 1990, foi ratificado na Argentina em maio de 1991 através da Lei n. 23.935 e pelo Brasil em julho de 1992, por meio do Decreto n. 619 . Sendo este o instrumento legal que regula as condiçōes de implantaçâo atividades das binacionais". 
Este instrumento jurídico constitui não somente base legal para as Empresas Binacionais, mas uma forma de alavancar as negociaçöes do Mercosul e conjugar os interesses comuns de ambos países.

A busca pela harmonização legislativa tem no Estatuto das Empresas Binacionais sua melhor representatividade, pois, sem alterar as forma societárias de cada país, criou uma lei única para que as empresas dos dois Estados interajam entre si ampliando portanto seus mercados.

Assim, justamente durante o encontro presidencial dos países do Mercosul, ocorrido em Las Leñas, Argentina, em 06 de julho de 1990 , concomitantemente com a segunda reunião do Conselho do Mercado Comum, que Brasil e Argentina trocaram os instrumentos de ratificaçăo do Estatuto das Binacionais.

No bojo de um processo de integração econômica, a empresa binacional constituí-se como forma eficaz e dinâmica de desenvolvimento do comércio e economias regionais. A principal caracteristica das binacionais é o alargamento regional da sua constituição e base de produçăo industrial, consequentemente ampliação do mercado consumidor.

\subsection{As Empresas Binacionais Argentino-Brasileiras}

Estatuto das Empresas Binacionais possibilitou conferir às empresas binacionalidade no pais de sua atuação, e mesmo tratamento estabelecido ou que venha a se estabelecer para as empresas de capital nacional desse pais, ainda que a maioria do capital social pertença a investidores de outro país.

Una vez constituida, a empresa binacional deverá, na verdade, estar sempre acompanhada das denominaçöes Empresa Binacional BrasilArgentina - EBBA ou Empresa Binacional Argentino-Brasileira (EBAB). Se a sede for no Brasil e a empresa atuar neste território, se utilizara a denominaca EBBA (Empresa Binacional Brasileiro-Argentina) e vice versa. Além dos beneficios, estão postas várias exigèncias, sem as quais não se

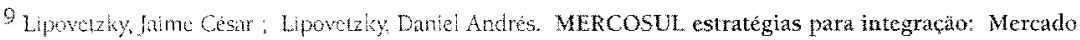
Comum ou Zona de Live Comercio? Analise e perspectuse do Tratado de Assuncuto. Sto Fato : LTr, 1994.
} 
caracteriza uma binacional nos moldes do Estatuto.

A empresa constituída está sujeita à ordem jurídica relativa às sociedades comerciais jâ adotadas e aceitas na legislação do Brasil ou Argentinat ${ }^{10}$. Portanto, são sociedades constituidas totalmente de acordo com os regulamentos da legislação brasileira ou argentina, acrescidas de conotaçós binacionais e obedientes ao espírito de um texto que visa ao desenvolvimento econômico comum dos paises signatários do Estatuto.

Assim, não há criação de um novo tipo societário". A empresa binacional deverá enquadrar-se nos tipos societários já previstos, ou que venham a ser criados pelo ordenamento interno. A análise da natureza juridica das empresas binacionais revela-se sem maiores conflitos ou incertezas jurídicas, vez que o Estatuto evita criar um tipo novo de sociedade, remetendo-se a formas já existentes e reconhecidas pelos ordenamentos dos Estados signatários. No tocante da natureza juridica das binacionais, de acordo com o Estatuto, são consideradas empresas nacionais reguladas pelo direito interno e não como pessoas de direito internacional, vez que tais empresas brasileiro-argentinas sempre seräo constituidas segundo as leis nacionais de um dos dois paises, ainda que seu regime tenha origem em um instrumento de direito internacional.

A nova empresa terá a natureza juridica da forma societánia a que foi constituída. A expressão revestirão utilizada no parágrafo primeiro, do artigo III, cio Estatuto das Binacionais, vem demonstrar que este instrumento jurídico nào constitui nova sociedade comercial no Direito brasileiro ou argentino $^{12}$.

Sendo este o entendimento da profa Maristela Basso ${ }^{13 .}$

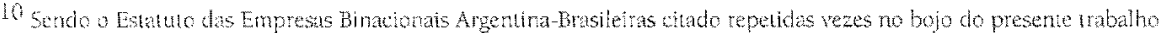

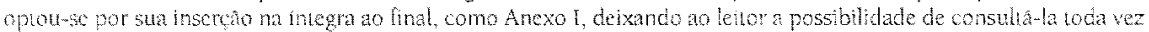
ane se fizet netestario.

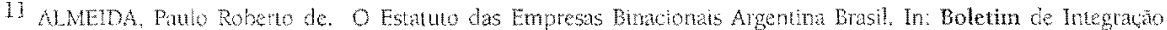
Latifom Americho, $1902, n^{\circ} 5,1,13$.

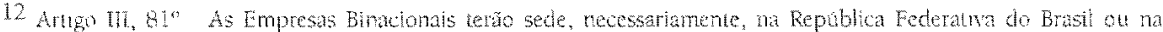

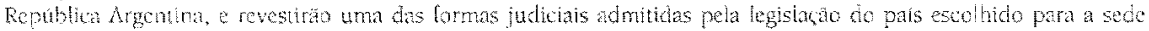

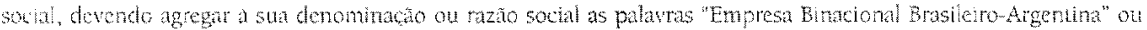

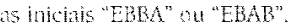


(..) o Estatuto não estabelece uma nova estrutura de direito interno, apenas agrega as estruturas previamente existentes nos dois paises determinadas exigências, que uma vez observadas se somam aos modelos societarios já existentes, conferindo-thes tratamento mais favorável.

As empresas binacionais contam com vantagens e privilegios para a transferencia de capital para sua constituição, para a remessa de lucros e deslocamento de pessoal, direitos esses que, teoricamente, seräo estendidos no futuro a todas as empresas situadas no Mercosul.

As empresas binacionais submetem-se ao regime jurídico do pais sede de sua constituiçäo, com a vantagem de que se presume sejam domiciliadas nos dois paises. Assim sendo, dispõe ele que as sociedades constituidas de acordo com os seus termos terão, no país em que atuarem e independentemente da composiçăo de seu capital, o mesmo tratamento dispensado ou que venha a ser dispensado às empresas de capital inteiramente nacional desse mesmo pais, em matéria de: a) tributaçăo interna; b) acesso ao crédito interno; c) acesso a incentivos ou vantagens de promoçăo industrial, nacional, regional ou setorial; ed) acesso às comprase contratos do setor público.

Além disso, foi estabelecido que os bens e serviços produzidos pelas empresas binacionais gozarão de tratamento prioritário, equiparado às empresas nacionais, na implementação, por ambos os governos, de iniciativas bilaterais desenvolvidas no contexto do processo de integração e cooperação econômicas ${ }^{14}$.

Apesar de ratificado no Brasil em julho de 1992, pelo Decreto n. ${ }^{\circ} 619$, somente em 1995 pode ter eficácia e aplicabilidade plena, com a emenda Constitucional n. $06 / 95$. Neste aspecto havia certa contradiça com a Constituição Federal brasileira no seu artigo 171, inciso II, onde o Estatuto das Binacionais encontrava entraves práticos, pois havia concessäo de

13 BAs50, Maristela. Joint Venturc... op. et. los., p.203.

14 Lipoverky, Jume César; Lipovezzky Daniel Andrés. op. el. Lox., p. 297. 
vantagens para a empresa brasileira de capital nacional.

O texto constitucional original definia como empresa brasileira de capital nacional aquela cujo controle efetivo esteja em caráter permanente sob a titulariedade direta ou indireta de pessoas fisicas domiciliadas e residentes no pais (...). A exigência não estava colocada de forma imperativa, ou seja, domiciliado e residentes.

Assim, o Estatuto conllitava com o texto constitucional em seu artigo $3^{\circ}$, letra $a$, onde admite como nacionais as pessoas físicas domiciliadas em qualquer dos dois paises, sem mencionar residencia.

Na legislação brasileira há diferenças entre domicilio e residência. 0 Código Civil brasileiro, em seu artigo 31, in verbis, o domicitio civil da pessoa. natural s o lugar onde ela estabelece a sua residencia com ânimo efetivo. Enquanto a Lei de Introdução ao Código Civil, nos attigos $7^{\circ}$ e $8^{\circ}$, refere-se ao domicílio especificando diversos casos de direitos de brasileiros e não brasileiros, nos quais se aplica a lei para pessoas residentes, nâo residentes e domiciliadas.

O Estatuto da Empresa Binacional define como condição para as pessoas fisicas postularem a constituição de uma binacional o simples domiclio no Brasil ou Argentina. Com a revogação do artigo 171, da Constituiçăo Federal brasileira, pela emenda $6 / 95$ foi resguardado o tratamento igualitário, bastando que as empresas tenham sido constituidas pelas leis brasileiras.

Além da questão do domichlio, havia restrição quanto ao capital, pois a constituiçäo brasileira favorecia a empresa brasileira de capital nacional, conforme artigo $171, \S 1^{\circ}$ e $\delta 2^{\circ}$. A política protecionista adotada pelo Brasil até entāo causava polemica, pois restringia quanto ao domicilio e distinguia a empresa brasileira de capital nacional, extinguindo a entrada de capital estrangeiro. Como o Estatuto das Binacionais considera como investidores nacionais tanto o argentino quanto o brasileiro, sua aplicabilidade gerou conflito. Todavia, houve manifestação doutrinaria no sentido de que o artigo 171, da Constituição Federal brasileira, não excluiria a aplicabilidade do Estatuto das binacionais no que tange à nacionalidade.

Neste sentido, manifestou-se o prof. Paulo Roberto de Almeida ${ }^{15}$, ao 
invocar os preceitos da integração, no artigo $4^{\circ}$, do texto constitucional brasileiro, e acrescenta:

Como a empresa binacional é um instrumento funcional e uma das modalidades mais adequadas ao objetivo da integração, ela não poderia ser contrária aos objetivos nacionais, tais como definidos no mesmo Titulo 1 da Constituiçäo, Em outros termos, o artigo 17 I não poderia ser utilizado para obstaculizar a integraçâo regional latino-americana.

Também salienta Paulo Roberto de Almeida a existencia do precedente Itaipu Binacional que goza de privilégios especiais e näo se enquadra na definição de empresa brasileira de capital nacional.

No que tange as binacionais argentino-brasileiras a norma contida no artigo 171 impede que gozem certos direitos oriundos da dupla nacionalidade, que seja, a presunção da residencia de seus responsáveis em ambos países. A eliminação da definiçăo de empresa brasileira de capital nacional e da permissão para que a lei estabelecesse benelícios em seu favor encerrou a celeuma.

Revogado o artigo 171, todas as leis e atos administrativos de mesma natureza restritiva foram automaticamente derrogados por inconstiucionalidade, seguindo-se o principio da imediata incidència das regras juridicas constitucionais.

Abre-se a possibilidade das binacionais desenvolverem joint ventures com empresas de mercados terceiros, além de ter efeitos práticos incentivando e desenvolvendo negócios entre Brasil e Argentina, a celeuma provou o retardamento na aplicabilidade o Tratado das Binacionais.

Retirado a restrição constitucional brasileira, as empresas binacionais podem livremente negociar qualquer objeto economico licito e previsto no ordenamento dos paises signatários. Cabe ressaltar ainda, quanto ao objeto das binacionais, que a Constituição brasileira restringe algumas atividades,

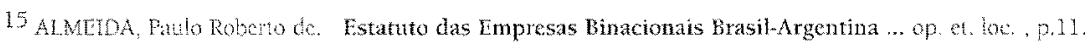


como o caso da exploração de veículos de comunicação, contida no artigo $222^{16}$. Na Constituição Argentina não constam tais restriçôes.

A constituição das binacionais dă-se, preliminarmente, através de um acordo onde constarão as condiçóes de constituição e geração da empresa binacional.

Entre os requisitos exigidos para que a empresa seja considerada como binacional argentino-brasileira, destacam-se os seguintes: 1) que pelo menos $80 \%$ do capital e dos votos pertençam a investidores nacionais da Argentina e Brasil; 2) que se assegure aos investidores nacionais o controle real e fetivo da empresa binacional; 3) que a participação do conjunto dos investidores de cada um dos países seja, pelo menos, $30 \%$ do capital social da empresa; 4) que o conjunto dos investidores nacionais de cada um dos paises tenha direito a eleger, como mínimo, um membro de cada um dos órgãos da administração e um membro do órgão de fiscalização interna da empresa ${ }^{17}$.

Para o cumprimento dos requisitos acima, são considerados investidores nacionais: a) as pessoas físicas domiciliadas no Brasil ou na Argentina; b) as pessoas juridicas de direito público de qualquer dos dois países; e c) as pessoas juridicas de direito privado de qualquer um dos dois países, nas quais a maioria do capital social e dos votos, e o controle administrativo e tecnológico efetivo sejam, direta ou indretamente, detidos pelos investidores indicados em a) e b) acima.

Todavia, o próprio Estatuto limita a condição de investidor nacional àquelas pessoas físicas ou jurídicas brasileiras e argentinas, que detenham, no mínimo, $50 \%$ do capital social da empresa, seja pública ou privada. Também impossibilita a ocorrência de açōes ao portador, vez que as açoes das empresas constituidas sob a forma de S/A devem ser nominativas, não transferidas por endosso ${ }^{18}$.

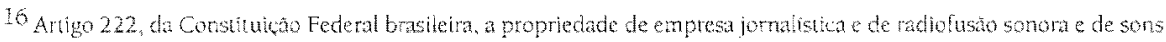

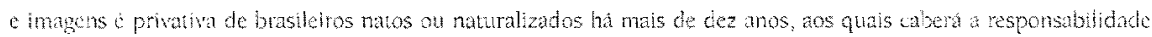
por sia admintraca on ontacto intelectual.

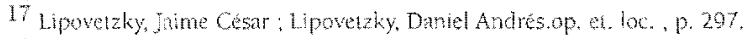

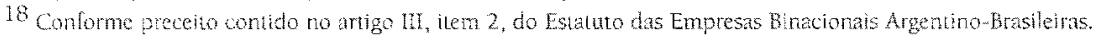


Isto serve para assegurar, na composição do capital social, o percentual mínimo de $80 \%$ para brasileiros e argentinos e um mínimo de $30 \%$ para um e outro. Previne-se, assim, a lomação do capital social para posterior venda de açoes com alteração na estrutura legal da binacional. No que diz respeito ao funcionamento das filiais, estas deverão obedecer à legislaça de seu pais hospedeiro, independente da matriz, no que diz respeito à forma, ao objeto e ao registro. A forma da binacional reproduzirá a forma da filial, seguindo-se o mesmo raciocinio, ou seja, se constituías na Argentina deveräo sê-las de forma diversa de sociedade anônima, pois a legislaço local não permite na forma de binacional.

Da mesma maneira, quanto ao objeto, a flial deverá seguir a legislaçăo do país hospedeiro, alem de que nenhum registro envolvendo-a poderá ser feito através da matriz, cada país detém seu órgão de registro especifico para as binacionais.

Foi constituido também um Comitê Binacional Permanente BrasileiroArgentino, onde o govemo brasileiro se faz representar pelo Ministro das Relacoes Exteriores, o qual detém a coordenação da seção nacional do organismo, com atribuiçoes estendidas ao subsecretário-geral de Assuntos de Integraçäo, Econômicos e de Comércio Exterior.

Os investidores da empresa binacional, conforme estabelece o artigo $4^{\circ}$, letra b, do Estatuto das Binacionais, têm a possibilidade de eleger a moeda comum aos seus empreendimentos, näo sendo necessariamente as moedas vigentes em seus paises. O tratamento dado a cobertura cambial é o ponto nodal das empresas binacionais, ou seja, a ausência de cobertura cambial nos paises receptores para aportes em bens de capital e equipamentos de origem brasileira ou argentina.

0 aponte de bens de capital facilita o objetivo do Estatuto, que é o econômico e näo juridico, qual seja, o fomento do desenvolvimento de. empresas entre os seus signatarios. Tais procedimentos deverão receber, necessariamente, de ambos governos, providencias para assegurar às transaçōes rapidez e eliciência, respeitados os acordos fimados no âmbito da Associaça Latino Americana de Integração - ALADI e por analogia, no Mercosul, assim como todas e quaisquer facilidades estabelecidas por alguns 
desses acordos deverão ser aplicadas às binacionais, conforme artigo TV, item 5, do Estatuto das Binacionais.

Denota-se, diante do exposto, a premissa básica do Estatuto das binacionais, a criação de condiçoes de competitividade entre empresas nacionais e binacionais, através da subssunção à mẹsma tributação interna e a permissão ao mesmo acesso de crédito. As binacionais poderão como as empresas de capital nacional, dispor dos mecanismos de crédito e incentivos disponibilizados, além de outras fontes que eventualmente vierem a ser criadas.

Estatuto das Binacionais prevê a transferencia ao exterior dos lucros auferidos $^{19}$, desde que cumpridas as obrigações tributárias. Este repatriamento respeitará sempre a participaçāo de cada um dos sócios na configuração da empresa. O repatriamento dos lucros acontecerá não por uma regra especial da binacional, mas sempre nos termos em que se estabelece este tratamento no país em que a empresa estiver sediada. Idèntico raciocínio é válido para as fillais ou subsidiárias da binacional, tenha ele sede no Brasil ou na Argentina.

A interligação entre o Banco Central, a Receita Federal e a Secretaria de Política industrial do Ministério da Indústria, Ciencia e Tecnologia do Brasil para evitar o descompasso no acompanhamento da binacional, no momento em que esse tipo de empresa for operacionalizada. Todavia, a outorga dos beneficios năo é discricionário ou facultativo da autondade competente, mas vinculado à satisfação dos requisitos exigidos pelo Estatuto ${ }^{20}$.

Cabe observar que o Estatuto das binacionais constitui-se como meio alternativo e não como norma imperativa, sendo opcional aos investidores a subsunção da joint venture à legislação especial.

\footnotetext{
19 Anigo VI Os investimeno de cada un dos paises em uma enpresa binacional estabelecida no cutro país terão direito, ura vez pagos os impostos que couberem, a transferir livernente gos respecivos paises de origem os lucros proventenes de sen truestimento, desde que distribuidos proportonalmente entre os investidores, de acotdo como

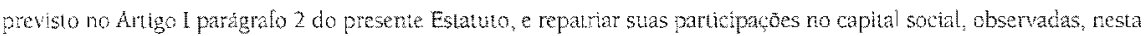
thima hipotese, as dispositges legais aplicadas em cada pas. Igual direiro cabera as fihis, sucursais ou subsidianias das empresas binacionais no tocante a seus heros liquidos.

20 BASSO, Maristela joint ventures op. et. 10\%, p. 203.
} 
Ponto importante e proposta que ora se laz é a extensão do Tratado Binacional Argentina-Brasil aos demais países do bloco, pois também são objetivos do Estatuto da Empresa Binacional tanto o fortalecimento dos laços de intercâmbio comercial entre Brasil e Argentina como proporcionar condiçōes às empresas dos dois países para geração de tecnologia própria.

\subsection{As Binacionais Argentino-Brasileiras como instrumentos viabilizadores da Liberdade de Estabelecimento no Mercosul}

A liberdade de estabelecimento das empresas não deve ser reconduzida à isenção da aplicação das regras em vigor no país de estabelecimento. A sua finalidade é proporcionar um acolhimento positivo às pessoas singulares e coletivas que pretendam estabelecer-se num EstadoMembro", não as sujeitando a condiçōes abusivas e diferentes das impostas aos nacionais. Entende-se, aqui, por condiçöes abusivas qualquer tratamento discriminatório que vise dificultar ou impedir o estabelecimento ${ }^{22}$.

Quando trata-se de fatores da produçäo, o Tratado de Assunção referiu-se a liberdade de circulação significando que qualquer pessoa poderá viajar intra-bloco sem sofrer nenhum tipo de restrição e instalar-se, a fim de trabalhar, transferindo quando quiser os lucros que obtiver no pais receptor sem necessidade de garantir custo adicional23.

Esta meta pode ser alcançada pela soma de esforços entre os países, buscando aplicar a base principiológica do Estatuto das Empresas Binacionais aos demais sócios do MERCOSUL, minimizando o impacto da integração.

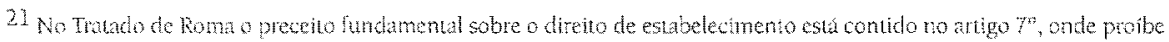

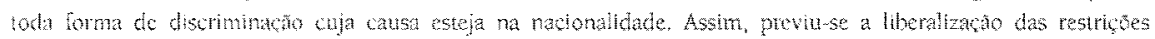

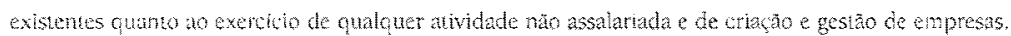

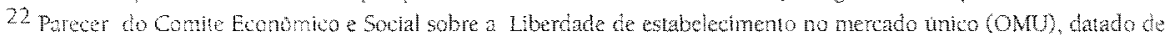

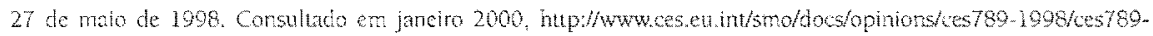
1998 ac_pthim.

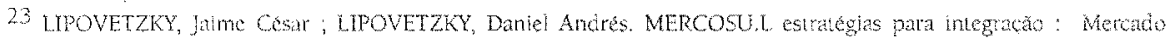
Conum ou Zona de Live Comécio? Análise e perspectivas do twato de Assunçăo. Săo Paulo : Lt, 1904. p. 84. 
Setores mais desenvolvidos no Brasil, como o têxtil, por exemplo, podem, através da Binacional, desenvolver de forma conjunta com os argentinos, em um ou no outro país, uma indústria de nível tecnológico elevado e produzindo em escalas económicas, nāo visando a competição no âmbito do Mercosul, mas especialmente em outros mercados.

Prevendo a necessidade de aportes financeiros constantes para o desenvolvimento de tecnologia, cujo custo é bastante elevado, o Estatuto da Empresa Binacional admite a possibilidade de transferencia de capital em moeda do país de origem, facilitando o fluxo de dinheiro entre os parceiros. Assim, uma binacional que tenha sido constituida no Brasil com capital majoritário de argentinos poderá fazer a inversão em pesos, ou seja: a moeda do parceiro que detém o controle acionário.

A questão da moeda entre os paises do Mercosul tem evoluido de maneira gradativa, porém firme, e em breve espaço de tempo provocará mudanças significativas na estrutura de comércio entre os pares. No Brasil, por exemplo, as relaçóes de compra e venda entre Brasil e Argentina têm a chancela do CCR (Convênio de Crédito Recíproco), que atribui uma garantia dos govemos centrais, em caso do descobrimento das operaçoes. Com a evolução dos negócios no Mercosul, o CCR passou de obrigatório a facultativo, e será, sem dúvida, um compromisso abandonado pelos pares. Isto porque a obrigaça fica mais a critério das partes envolvidas nos negócios, desde as empresas até os agentes bancários que autorizam as operaçóes.

Contudo, esta manobra depende fortemente de latores macroeconômicos que possam estabelecer condiçoes equitativas entre os parceiros, conferindo às moedas de cada país força e credibilidade.

Independente desta questäo, argentinos e brasileiros podem apottar em um e no outro país, seja o peso, seja o real, a partir do momento em que estiverem operacionalizando uma empresa binacional nos respectivos países. Estender tais vantagens aos demais países é aplicar a liberdade de circulaçäo preconizada. Claro que ajustes normativos e econômicos devem ser realizados, todavia muito estaria simplificado no processo harmonizativo. 
A fim de dirimir os conflitos de caráter internacional que se poderiam suscitar, no que pertine a existência das sociedades constituídas no estrangeiro, convém determinar a legislação aplicável em cada caso ${ }^{24}$. Atualmente, entre Argentina, Paraguai e Uruguai, já não discute-se o reconhecimento de pleno direito da personalidade jurídica das sociedades constituídas no estrangeiro, aos efeitos de sua atuação internacional, todavia estes Estados reservam-se a faculdade de requerer prova de forma e constituição, tal como demonstrado anteriormente pelas disposições legais dos países que integram o Mercosul.

Com efeito, o artigo $3^{\circ}$, da Convenção Interamericana de Montevidéu de 1979 sobre conflitos de leis em matéria de sociedades mercantis estabelece:

As sociedades mercantis devidamente constituidas no Estado serão reconhecidas de pleno direito nos demais Estados. O reconhecimento de pleno direito não exclui a faculdade do Estado para exigir comprovação da existência da sociedade conforme a lei do lugar de sua constituição.

Visando facilitar e agilizar a atuação internacional das sociedades constituídas no estrangeiro, o artigo $2^{\circ}$, da referida Convenção, estabelece:

A existência, capacidade, funcionamento e dissolução das sociedades mercantis se regem pela lei do lugar de sua constituição. Pela lei do lugar de constituição se entende a do Estado onde se cumpram os requisitos de forma e fundo requeridos para a criação de tais sociedades.

Com tais normas aprovadas e ratificadas pelas Republicas Argentina, Paraguai, Uruguai e recentemente pelo Brasil ${ }^{25}$, tem-se superado, nesta matéria, as limitações dos Tratados de Montevidéu de 1889 e 1940, que estabelecia que a lei do lugar do domicílio era a que regia as sociedades estrangeiras quanto sua capacidade e existência, tal como consta na legislação do Paraguai.

\footnotetext{
24 KIRMER, José Raúl Torre op. et. loc. p. 52.

25 Que ocasionou a revogaç̃o do artigo 171, da Constituição brasileira, através da Emenda Constitucional n" 6, de 15 de agosto de
} 
Assim, buscar os mecanismos adequados para que não ocorram conflitos sobre tais temas no âmbito do Mercosul é sempre uma premissa, no caso das sociedades estrangeiras, apesar da Convenção de Montevidéu, no Brasil ainda faz-se necessârio reduzir as exigencias formais para agilizar a autorização governamental para o funcionamento de sociedades estrangeiras.

De sorte que, um instrumento apto a atender as necessidades regionais poderia ser criado a partir do Estatuto das Binacionais, inserindo-se os quatro paises partes e elaborando-se tratados bilaterais, entre os mesmos. Atentando-se também ao conteúdo do regime a ser adotado, o Estatuto vigente baseia-se na concessão de benefícios, em detrimento às estrangeiras.

\section{Conclusão}

Fato notório e exarado do presente estudo consiste que, as empresas vinculadas ao processo integracionista necessitam, na verdade, é a remoção de entraves para suas operações em diversos países, e não a definição de um ordenamento exaustivo em termos juridicos.

Pode-se inferir que as associações empresariais, denominadas joint venture" säo o ponto principal para a alavancagem do crescimento nas negociaçöes comerciais sobretudo porque riquezas de ambos os paises circulam mais facilmente atingindo um mercado consumidor muito mais amplo. As empresas binacionais, como espécie deste gênero, portanto, apuram uma receita maior pois são voltadas exclusivamente para o mercado regional dos paises que formam o Mercosul.

No que tange a harmonização, o ordenamento mais importante, $e$ economicamente mais funcional, para o processo de integração avançar é principio do tratamento nacional, pelo qual as empresas de outros paises, e, neste caso as binacionais, gozam dos mesmos direitos e vantagens que säo oferecidos às empresas puramente nacionais

Una empresa binacional pode ser considerada o tipo ideal para aqueles paises que desejam participar de um processo de integração econômica, tal 
como é o Mercosul (Mercado Comum do Cone Sul) e aliás, vem sendo reconhecido desde o fim da década dos anos 60, quando iniciavam-se em várias partes do mundo a formaçäo de blocos comerciais entre os países, com o intuito de dinamizarem e desenvolverem o comércio e as economias regionais.

Como exara-se deste trabalho, sem dưvida que a abertura de uma filial de determinada empresa é mais facilitada do que a constituição de uma empresa binacional, mas para uma companhia que tem o staus de binacional os privilégios tributários e allandegários, por exemplo, săo bem ampliados, ante a própria previsão do Tratado de 06 de junho de 1990.

Com efeilo, em uma estrutura binacional ou plurinacional do capital, que é em suma a alma de qualquer empresa, estas estarão totalmente voltadas para o processo de integraça regional, o que aumenta demasiadamente o seu poderio competitivo pela circunstância de que estará exclusivamente estruturada para atuar junto ao Mercosul, mercado cujos lineamentos e fundamentos são diferentes da atuação dentro de um âmbito restritivamente nacional.

As decisões serão controladas e localizadas nos próprios países integracionistas e em especial com metas voltadas, para os mercados consumidores da região do mercado comum. As empresas binacionais produzita conforme as necessidade do mercado regional, sempre atenta às translomacoes economicas e políticas, de acordo com o que for estabelecido pelos paises componentes do bloco econômico.

\section{BLBLIOGRAFIA}

ACORDAOS Reyners de 21 de Junho de $1974(2 / 74)$ sobre a liberdade de establecinento ALRES, Latro. Brasil torna Paragua Socio Privilegiado. Gazea Mercantil Latino Americana, $28 / t e v a$ $05 /$ mat Cutiba: 2000 . p. 25.

ALMTDA, Hamilton. Argentina ajudará indústrias. Gazeta Mercantil Latino Americana, 13 a 19 mar. Curita: 2000 , p. 25.

A1MIIDA, Hamiton, De Olho no Brasil, Quimicas argentinas formam "pool". Gazeta Mercantil Latino Ancricam, 10 n 16 fan. Curitiba : 2000 . p. 19. 
ALMEIDA, Hamilton; MANAUT, Sérgio \& VILAS, Oscar. Têxteis e Calçados Terão Novos Acordos. Gazeta Mercantil Latino-Americana, 27/mar à 02/abr. Curitiba : 2000. p. 27.

ALMEIDA, Paulo Roberto de. O Estatuto das Empresas Binacionais Argentina Brasil. In: Boletim de Integração Latino-Americano, $1992, n^{\circ} 5$.

ALONSO, Ursula. Linhas de Crédito para Brasileiros no Exterior. Revista do Mercosul, jan/fev. São paulo: 2000 . p. $46 / 47$.

ARAUJO, Juliana Correia de. Aspectos legais da atuação empresarial no MERCOSUL - evolução e aspectos atuais da questāo. In: MERCOSUL : Liçōes do periodo de transitoriedade - Celso Ribeiro Bastos (coord) São Paulo : Instituto Brasileiro de Direito Constitucional, 1998.

ARGENTINA. Código de Comercio y Leyes Complementares. Editorial Estudio : Buenos Aires (cópias de algumas leis: Ley de seguros, Sociedades Comerciales, Cooperativas, Obligaciones Negociables, Fondos Comunes de Inversion, Defensa Del Condumidor, Transporte Multimodal de Mercadorias, Factura de credito).

As economias do Mercosul. Revista do Mercosul, jan/fev. São Paulo: 2000. p. 36/38.

BAPTISTA, Luiz Olavo. Os investimentos internacionais no Direito Comparado e Brasileiro. Porto Alegre : Livraria do Advogado, 1998.

BASSO, Maristela. Joint ventures, manual prático das associações empresariais. Porto Alegre : L.ivraria do Advogado, 1998.

BASSO, Maristela. Mercosul, seus efeitos jurídicos econômicos e políticos nos Estados-membros, 2 ec. Porto Alegre: Livraria do Advogado, 1997.

BRASIL. Lci 6.404/76. Lei das Sociedades Anonnimas. Código Comercial Brasileiro e Legislaçăo Comlementar: 30. ed. São Paulo: Saraiva, 1985.

BUtgareLLI, Walclomiro. Tratado de Direito Empresarial. 3. ed. São Paulo: Atlas, 1997.

CASEILA, Paulo Borba. Contratos Internacionais e Direito Econômico no Mercosul. São Paulo: LTr, 1996.

COMPARATO, laabio Konder. O poder de controle na sociedade anônima. Säo Paulo: RT, 1976

COSTA, Carlos Jorge Sampaio. O Código de Conduta das Empresas Transnacionais. São Paulo

Forense.

ESCOBAR, Jorge H. Derecho Comercial. Assunción : La Lei Paraguaya S.A., 1997.

FARIA, José Eduarco. O Direito na economia globalizada. São Paulo : Malheiros Editores, 1999.

FONTOURA, Jorge. Assimetrias Constitucionales en el Mercosul. Mercosul Informativo, São Paulo, n. 10, p.5/.0

FRONTINI, Paulo Salvador Itaipu Binacional: Novo Tipo de Empresa? In: Revista de Direito Mercantil, n. ${ }^{\circ} 15 / 16,1974$, p. 38/39.

GHERSL, Carlos A. Funciones y Responsabilidad de la Empresa en el Mercosul. Revista dos Tribunais, São Paulo, v. 723, jan. 1996.

GRINBERG, Mauro. O Direito Brasileiro da concorrência empresarial e o Mercosul. In: BASTOS, Aurélio Wander (org.). Estudos Introdutórios de Direito Econômico. Brasília: Brasilia Jurídica, 1997

JESSUP, Philip C. Direito Transnacional. Rio de Janeiro : Fundo de Cultura Brasil-Portugal, 1956.

KIRMSER, José Raúl Torres Reflexiones ante la Problemática Jurídica del Mercosur - El Derecho frente al Desafio de la Integración Intercontinentel Editora: Assunción, 1998

LEVY, Luiz Fernando Ferreira. Um Programa integtado para o desenvolvimento do Mercosul. Gazeta Mercantil Latino Americana, 03 à 09/abr. Curitiba : 2000. 
Lipovetzky, Jaime César ; Lipovetzky, Danel Andrés. MERCOSUL- estratégias para integraçăo: Mercado Comum ou Zona de Livre Comércio? Analise e perspectivas do Tratado de Assunção. São Paulo: LTr, 1994. CAUBET, Chistian Guy, As grances manobras de Itaipu : energia, diplonacia e direito na Bacia do Prata. Săo Paulo: Academica, 1989.

LOEO, Jorge. Direito dos Grupos de Sociedades. Revista dos Tribunats, Săo Paulo, ₹63, p. 24. Maio 1999

MAYER, Liliz Rafael. Parecer L-208, de 22/09/78; Natureza Juridica de Itaipu. Consultoria Geral da Republica, de 19/1078, p. 16869-16877.

MELLO, Celso Antonio Bandeira de Curso de Direito Administrativo. Ged. São Patlo : Matheiros Editores, 1995.

MIRANDA, Pontes de. Comentários à Constituiçäo de 1967.Tomo V1, Revista dos Tribunais, São Paulo, 1968, p. 369. Apud FRETAS, Ailton Carvalho. Parecer conjud. N. 268 , publicado no D.O.U. de 13 fev 1906, Secio 1, p. 2475-2477.

NASSER, Rabih AIi . A Liberaçăo do Comércio Intemacional nas Normas do GATT - OMC. Săo Paulo : LTR, 1999.

OLVEIRA, Odele Maria de. Uniào Européia: processo de integraçao e mutaçá. Cunitiba: Juruá, 1999 .

PARAGUAI, Codigo Civil Paraguaio y leyes complementarias. Assuncão: Intercontinental, 1999.

QUES, Juan Tugores. Economia Internacional e Integracion economica. 2. ed. Madrid : MacGraw Hill, 1906.

REQU1aO, Rubens Curso de Direito Comercial. 19. ed anal, Săo Panlo: Saraiva, 1993 p. 215 . v 2. REZEK, Jose Francisco. Dircito Internacional Público: curso elementar. 7.ed. Săo Paulo: Saraiva, 1998.

RiGGl, Horátio. Pasa ameaça transferir-se para o Brasil. Gazeta Mercantil Latino Americana, 03 a 09fjan. Cuntiba: 2000.

STRENGER, Irimen. Direito do Comércio Internacional e Lex Mercatoria. Säo Paulo : LTr, 1996.

TAMAMES, Ranón. La Union Europea. Madrid : Ahanza Editorial, 1994.

Tratado entre o Brasil co Paraguad, de 26.04 .73 , ratificado pelo Decreto n. 72.707 , de 28.08 .73 , que promulga o texto do Tratado, bem como as seis Notas trocadas entre os Ministros das Relacöes Exteriores dos dois parses. 